\title{
FEASIBILITY AND ISSUES OF RURAL TOURISM BASED ON INTER-INDUSTRY COOPERATION
}

\author{
Seiichi Sakurai ${ }^{1}$, Shingo Teraoka ${ }^{2}$ \\ ${ }^{1}$ Graduate School of Horticulture, Chiba University, Japan. \\ ${ }^{2}$ Faculty of Letters, Nara women's University Kitauoya-Nishimachi, Japan. \\ Corresponding author: tera@cc.nara-wu.ac.jp
}

Citation: Sakurai, S., and Teraoka, S. 2020. Feasibility and Issues of Rural Tourism Based on InterIndustry Cooperation. J. Asian Rur. Stud. 4(1): 88-97

\begin{abstract}
The study described herein was conducted to identify general aspects of rural tourism based on the Inter-Industrial Cooperation Project in Japan and to investigate factors and background obstacles to sustainable development of rural tourism management through collaborative organization of various actors. Most approved projects are engaged in producing and marketing local specialty goods. The numerous projects aiming at initiating tourism activities are extremely small. Some approved projects targeting tourism management have already been abandoned. The authors conducted interview surveys to elucidate some typical cases, which elicited the following points about hindrances to sustainable development of rural tourism management based on the Inter-Industrial Cooperation Project: difficulty of maintaining collaborative networks among actors of various types; unexpected tourism-related risks; vulnerability to demands of tourism industry; and the mismatch between the system of national projects and needs for the practice of tourism activities. Results of two case studies underscored these obstacles. The authors finally described the role played by actors outside the rural village and local government officers for improving future collaboration projects.
\end{abstract}

Keywords: Diversification, inter-industrial cooperation, revitalization, rural economy, rural tourism, sustainable development

\section{Introduction}

Tourism is an important aspect of farm and rural revitalization. Many rural villages have strived to introduce tourism to enhance and diversify rural economies. Although farm village tourism has been steady in some cases, many villages have been unable to continue their tourism businesses.

For revitalization of businesses, including agriculture, to contribute to sustainable local development, the businesses themselves must be sustainable to begin with. Nevertheless, such businesses have been implicated in some earlier studies as generally operating on a small scale, with emphasis on the processing of local specialties. Moreover, their networks with local economic agents remain inadequate. 
Resolving these difficulties necessitates cooperative effort at developing tourism, local businesses, civic groups, agricultural, commercial and industrial operators, and other organizations. Such cooperation, however, has rarely been a hallmark of tourism in the past. Many businesses confront ongoing difficulties.

The Japanese government established the Inter-Industrial Cooperation Project to enhance collaboration among different sectors in local economies. Nevertheless, many approved projects have targeted processing and marketing local specialties. Few projects target the initiation of service industries, including rural tourism, through collaboration.

Experts interested in rural economies and societies have investigated rural tourism. Generally speaking, agricultural economists have investigated the multifunctionality or external effects of rural tourism management, whereas rural sociologists and geographers have assessed rural-tourism-related relations among actors and organizational characteristics (Slee et al. 1997; Ohe 2006).

Teraoka reviewed studies of rural tourism in Japan and Europe and subsequently described two important emphases of recent studies: 1) consideration of the importance of a mobile society and 2) consideration of collaboration among various sectors for the practical management of rural tourism (Teraoka 2017).

Studies emphasizing a mobile society perspective are associated with the New Mobile Paradigm (NMP) proposed by Grieco and Urry (2011). In a mobile society, some city residents visit a rural area repeatedly. The boundary between visitors and rural residents becomes ambiguous. Some visitors spontaneously make statements about the activities of rural community, thereby becoming actors abetting rural tourism management (Franklin 2013).

The repeated visits of tourists and other actors from outside the rural area alter the network among actors and stakeholders and the structure of organization related to rural tourism management. This trend can also be regarded as progressing from collaboration to integration. Cawly and Gilmour proposed Integrated Rural Tourism (IRT), for which they presented a model of collaboration and management among different sectors. They also described the importance of embedding the new system into the rural community and economy (Cawly \& Gilmour 2008).

In Japan, Morishige proposed the Open Platform concept, which enables various actors, including those outside the rural community, to join the platform for community development (Morishige 2014). 
Based on the above background, the paper elucidate the factors and background characteristics obstructing the sustainable development of rural tourism activity based on the Inter-Industry Cooperation Project in Japan.

\section{Method}

The study methodology includes the following: First, the authors present an outline of the Inter-Industry Cooperation Project. After confirming rural tourism research trends, the authors investigated summaries of planning documents submitted by project applicants and clarified the general characteristics of rural tourism practices applied for the Inter-Industry Cooperation Project. Two case studies demonstrate important matters confronting actors during the practice of rural tourism with collaboration between the farming sector and commerce/industrial sectors. Finally, the authors summarize research results and explain future issues related to the continuous development of rural tourism.

\section{Result and Discussion}

\subsection{Inter-Industry Cooperation Project in Japan}

In 2008, the Ministry of Economy, Trade and Industry (METI) and Ministry of Agriculture, Fishery and Forestry (MAFF) introduced the Inter-Industry Cooperation Project to enhance local economies and to boost collaboration between the agricultural sector and industrial sector (both manufacturing and commerce) on a regional basis. The applicant farms and local small to medium-size enterprises (SMEs) are expected to plan joint projects for boosting collaboration and for enhancing local economies. The approved projects are entitled to support in the form of expert advice, subsidies, loans from government-run financial institutions, credit guarantees, etc. As of February 2018, the government had approved 773 projects.

Table 1 presents a distribution of main objectives of all approved projects. Higher objectives are closely related to the production or marketing of local products, especially agricultural products. This fact implies that many approved projects are intended to produce and market agricultural products or processed foods. By contrast, few projects target service industry development, such as that of tourism. The structure of coordination among agriculture, commerce, and manufacturing on each approved project affirms this trend. As of 2010, 68\% of the projects included collaboration between the farming sector and manufacturing sector, whereas the collaboration of all three sectors and collaboration between the farming sector and commerce sector 
respectively accounted for $25 \%$ and $7 \%$ (Sakurai 2011). The commitment of the commerce sector is weaker than that of either the agriculture or manufacturing sector. Some products should be sold. Therefore, marketing is examined for many approved projects targeting local products. Nevertheless, other service activities such as tourism are not often introduced into the approved projects.

Table 1 Main Objective of Approved Inter-Indstry Cooperation Projects

\begin{tabular}{lrr}
\hline \multicolumn{1}{c}{ Objective } & $\begin{array}{c}\text { No. of } \\
\text { projects }\end{array}$ & Proportion \\
\hline Demand creation and branding of local agricultural products & 357 & $46.2 \%$ \\
Demand creation of new agricultural products and varieties & 179 & $23.2 \%$ \\
Utilization of agro-resources and unused resources & 118 & $15.3 \%$ \\
Adding value to agro-products by eco-friendly farming & 50 & $6.5 \%$ \\
Production or marketing utilizing new technologies & 44 & $5.7 \%$ \\
Marketing channel diversification by cooperating tourism & 16 & $2.1 \%$ \\
Export of local products & 9 & $1.2 \%$ \\
\hline Total & 773 & $100.0 \%$ \\
\hline
\end{tabular}

Source: MAFF, Japan

\subsection{Cases of Inter-Industry Cooperation Project Engaged in Tourism}

Summaries of plans of all approved Inter-Industry Cooperation Projects are presented on the homepage of an agency supporting SMEs in Japan. An investigation of the summaries revealed only nine cases aimed at developing rural tourism or tourism using rural resources. Among those nine cases, four cases had already ceased tourism activities. In one case, the applicant enterprise had already closed its business. Establishing and continuing rural tourism commercially is extremely difficult. The authors conducted interview surveys to assess three cases, using telephone and e-mail surveys in two cases. The survey results revealed several important factors and background characteristics affecting the difficulty in continuing rural tourism and related activities.

First, forming a continuous network between the farming sector and the commerce/ manufacturing sector is difficult. In general, farm households and agriculture-related organizations have fewer opportunities to communicate with commerce and industrial enterprises, despite being in the same region. Usually, much time is necessary to become mutually acquainted and to change information precisely. Furthermore, misunderstandings stemming from weak networks sometimes arise. 
Secondly, unexpected risks related to rural tourism disturb the continuous management of tourism activities. In general, visitors do not know much about farming practices. They sometimes have inappropriate practices that can cause accidents. In addition, because many rural tourism activities are held in open areas, tourism events are often influenced by weather changes. Sometimes these risks can be alleviated by adopting an insurance system. However, an insurance company cannot assess all tourism-related risks. It is difficult to establish an insurance instrument that can cover tourism-related risks of all types.

Thirdly, tourism demand is a point of vulnerability. Although the total demand for tourism is increasing steadily in Japan, unexpected accidents and changes of social situations often lead to decreasing demand for services, including tourism. A salient example is the influence of natural disasters. In 2011, the strong earthquake occurred in eastern Japan, with an ensuing accident at a nuclear power station in Fukushima. Confusion deriving from these disasters caused the avoidance of tourism activities throughout Japan. The number of tourists decreased sharply. One approved project described above had planned to call city residents to a farming experience business in coordination with a travel agency. However, the plan was cancelled immediately after the Great East Japan Earthquake.

Finally, mismatches between systems and practices often arise in relation to tourism activities or food manufacturing and food services. The mismatches often arise when applicant farms and enterprises use subsidies supported by the project. When the government established the Inter-Industry Cooperation Project, the government intended to give subsidies for activities aimed at collaboration among actors. It is therefore difficult for the applicants to obtain subsidies for procuring facilities and tools compared to cases in which they conduct events for collaboration among applicants and their stakeholders.

\subsection{Case Studies}

\subsubsection{Wani farm: Difficulty of continuing tourism activity in rural areas}

Wani farm is conducting rice production and marketing by commission with neighboring small farm households. In addition, Wani farm has provided city residents with opportunities for farming experiences such as rice transplantation and harvesting for a fee.

To expand farm experience opportunities and to make a healthy business, Wani farm collaborated with a local hot spring inn and gained approval as an Inter-Industry 
Cooperation Project in 2012. This project was aimed at 1) providing opportunities to enjoy farming experience at Wani farm and 2) tasting local dishes cooked by the skillful chef of the inn. The Wani farm tried new farming experience programs with the local inn. Nevertheless, they ceased offering this activity a few years later.

The Wani farm manager pointed out the following reasons for abolishing the collaboration project. First, they confronted some unexpected risks when they practiced farming experiences with tourists, such as the danger of tourists' injury at the farms, the risk of traffic accidents between the inn and farmland, and the risk of food poisoning stemming from food preparation and cooking. These risks can be mitigated through insurance to some extent. However, it is difficult to estimate risks of all kinds and adopt insurance for experiences of all kinds. Secondly, the tourists themselves do not understand the risks described above. Many tourists apply for experience casually without considering the risks. Some of them undertake dangerous and inappropriate actions and must then confront the consequent hazards. Thirdly, there are many tight regulations related to tourism business. Local farms and enterprises have difficulty understanding those regulations and taking proper procedures. As one example, many strict rules on passenger traffic exist in Japan; general enterprises cannot send tourists to a destination using their own transportation facilities. They must consign transportation to licensed transportation companies. Fourthly, local government officials have no expert knowledge related to the Inter-Industrial Cooperation Project. When the approved farms and enterprises begin the project, they often require local government advice and support. However, because this system was initiated by the national government (METI and MAFF), local government officers have no details for implementing this project. Finally, rural people have not been accustomed to providing hospitality to foreign tourists. The number of foreign tourists is increasing steadily in Japan. Many foreign tourists who are interested in traditional culture and local industry including agriculture often encounter misunderstandings or miscommunication in villages.

\subsubsection{Michi-no-eki Hota Primary School: various actors' participation and future} issues

Michi-no-eki, which literally means a "railway station by the road" is a facility for drivers to take a rest. It comprises a rest area, an information booth, and a shop selling goods. Michi-no-eki has been promoted by both national and local governments since the 1990s. Japan has approximately 1,000 Michi-no-eki facilities, especially in rural 
areas. Some Michi-no-eki locations attract many tourists from urban areas by offering local products and resources. Therefore, some municipalities in rural areas have tried establishing a new Michi-no-eki for local economy enhancement. Michi-no-eki facilities also draw tourists' attention because they can obtain local information, buy local products at a shop, and sometimes enjoy meals at a restaurant.

Kyonan town, located approximately $100 \mathrm{~km}$ from Tokyo, has beautiful seashore and peaceful mountainous surroundings. Kyonan town is rich in attracting rural resources despite being located not so far from Tokyo and other big cities. Therefore, the town office began to establish Michi-no-eki facilities in the town to entice tourists to visit by car.

In many Michi-no-eki locations, local governments constructed facilities. The daily operations of the facility are conducted through joint ventures of local enterprises and agriculture-related organizations such as the commerce and industry associations and agro-cooperatives. However, when Kyonan town began to design facilities and to organize a committee for daily operation of the Michi-no-eki, the town office strove to introduce people and organizations from outside Kyonan town to adopt various ideas that might contribute to innovative management of the Michi-no-eki. At the design stage of the facility, the town office conducted a competition. A plan presented by a team of college lecturers was accepted. Daily operation of the facility was entrusted to a company engaged in hotel and dormitory management. During the screening of enterprises engaged in restaurant and souvenir shop operation, both local enterprises and companies located in urban areas were selected. When the town got a new organization of farmers' market operation, the town took more than one year to encourage various farmers' participation in the town, including farmers who were women, who were aged, and who operated small-scale farms. For farmers with less experience in selling products directly to consumers, the new farmers' market association conducted seminars with tips for improving production-related techniques and marketing practices.

This new Michi-no-eki is constructed at a closed primary school. The new Michi-noeki has adopted the name "Hota Primary School". The primary school serves as a community center and as a symbol of the local community for local residents. The closing of primary schools because of decreased population, especially the population of younger people, has imparted a psychological burden on residents. However, the restoration of the school as a new Michi-no-eki has vitalized residents, some of whom are engaged in new activities at the Michi-no-eki as part-time facility workers, shipping 
agricultural products to the farmers' market. The Michi-no-eki also opened an accommodation facility using a former school building. It welcomes tourists for overnight stays.

The Michi-no-eki in Kyonan town encouraged planning and management at the first stage. However, this Michi-no-eki is confronting new issues to be resolved for additional development. First, although various actors have become members of the committee of the Michi-no-eki operation or the shipping farmers' organization, traditional and sometimes conservative actors of the local economy, such as members of local commerce and industry associations and leading members of agro-cooperatives, are not active in the daily Michi-no-eki operations. The committee must prepare opportunities to collaborate with new actors and traditional actors. Secondly, visitors wish to participate in farming experience activities, but few farms can take in such tourists. Farm household members should acquire hospitality skills to accommodate visitors.

The practices of Kyonan town have not used the Inter-Industrial Cooperation Project. Nevertheless, their practices are indicative for consideration of issues related to rural tourism based on the Inter-Industrial Cooperation Project.

\section{Conclusion}

Although rural tourism has been targeted as an important and effective activity to revitalize rural economies in Japan, many earlier cases have been managed by individual farm households or small groups of farm households. The sustainability of tourism management is at a critically important stage. To enhance farming sector and commerce/industrial sector collaboration, the government established the Inter-Industry Cooperation Project. Nevertheless, this project is adopted mainly for collaboration in producing and marketing local products. Successful cases exhibiting enhanced service industries, including rural tourism activity, are scarce.

The authors investigated summaries of the plans of approved projects and conducted interview surveys to clarify the factors and background characteristics obstructing the sustainable development of practices of rural tourism management through the collaborative organization of various actors. Several matters were elucidated, such as the difficulty of maintaining collaborative networks among actors, unexpected tourismrelated risks, vulnerability to tourism industry demands, and the mismatch between the national project system and needs for adopting standard practices prevailing with tourism activity. Results of two case studies underscore the findings described above. 
Among the difficulties described above, some can be improved to some degree. Regarding the continuity of organizations, rural actors should partially admit the entry of actors outside the area because the operation of tourism activity requires various and sometimes intangible skills. It is difficult to find sufficient human resources within a small rural community (Morishige 2014). In addition, some repeat visitors and experts interested in the community concerned have a strong commitment to the community and can provide comments that might be effective for improving rural tourism practices (Teraoka 2017).

Another matter to be improved is the mismatch that arises from the options of InterIndustry Collaboration project set by the national government. In general, the system options are intended to support the formation of collaboration among actors (Sakurai 2011). However, in many practical cases, actor needs are more specific. The government should apply a supporting system according to changeable and concrete needs at the site. Local government officers usually know more about the actual situation of the project site and rural community (Cawly \& Gilmour 2008). Therefore, the national government should cooperate with the local government for the adoption of system support at the site.

\section{References}

Cawly, M. \& Gilmour, D. A. (2008). Integrated Rural Tourism: Concepts and Practice. Annals of Tourism Research, 35(2), 316-337.

Franklin, A. (2013). Tourist Studies. In P. Adey \& D. Bissell (eds.) The Routledge Handbook of Mobilities, 74-84. London: Routledge.

Grieco, M. \& Urry, J. (eds.) (2011). Mobilities: New Perspectives on Transport and Society, Farnham: Ashgate.

Morishige, M. (2014). Regional Revitalization by Tourism. Tokyo: Gendai Tosho. (in Japanese)

Ohe, Y. (2001) On the Relationship between Multifunctionality and Hamlet Activities as a Rural Institution. Japanese Journal of Rural Economics, 3, 36-50.

Sakurai, S. (2011). Issues on the Development of Plans for the Agriculture, Commerce and Industry Collaboration Program. Agricultural Marketing Journal of Japan, 19(4), 62-67. (in Japanese)

Slee, B., Farr, H., \& Snowdon, P. (1997). The Economic Impact of Alternative Types of Rural Tourism. Journal of Agricultural Economics, 48(2), 179-192. 
Teraoka, S. (2017). The Significance of Rural Tourism Studies Focusing on Mobility. Tourism Studies Review, 5(1), 79-92. (in Japanese) 